\title{
Evolving Diplomacy of Regional Organizations - Some Experiences in Balkans
}

\author{
Fejzi LILA
}

$\mathrm{PhD}$ candidate, European University of Tirana, Albania

\begin{abstract}
The regional organizations are becoming more and more the necessity of modern times. On vertically approaches the regional diplomacy and organizations are between international and national level of governmental institutions worldwide. Being in between global national levels the regional organizations are very interesting players to bring both above mentioned actors closer to each- other and to harmonize some time their contradictory approaches and interests. On horizontal approaches the regional organizations are located and operate in the common valuable areas with more or less the same or similar situations, in the common political landscape, in the same geography, geo-strategy, culture and markets. Therefore, they share the achievements and challenges together. That is why the increasing role of multilateral diplomacy through evolving regional organizations is very important facilitating mechanism to shift from old fashion bilateral oriented diplomacy toward globalization trends.
\end{abstract}

Keywords: Regional organization, multilateral diplomacy, local, regional, global.

\section{Introduction}

Multilateral diplomacy based on regional organizations is becoming more and more the necessity of modern times to bring the diplomatic synergy towards the best and efficient solutions. On vertically approaches the regional diplomacy and organizations are between international and national level of governmental institutions worldwide. The regional organizations could be considered as the bridge between national and global level of cooperation.

Being in between global national levels the regional organizations are very interesting players to bring both above mentioned actors closer to each others and to harmonize some times their contradictory approaches and interests. In the same time these in between actors should and could be very relevant multilateral organisms to serve as facilitators in bilateral problems on national levels. Regional organizations through their multilateral diplomacy can very quickly respond as a preventive diplomatic mechanism avoiding deteriorating of problems and situations and paving the way for long lasting solutions.

On horizontal approaches the regional organizations are located and operates in the common valuable areas with more or less the same or similar situations, in the common political landscape, in the same geography, geo-strategy, culture and markets. Therefore, they share the achievements and challenges together. That is why the increasing role of multilateral diplomacy through evolving regional organizations is very important facilitating mechanism to shift from old fashion bilateral oriented diplomacy toward globalization trends.

But to play such a unique role, the regional diplomacy and organizations need to reconsider their position and mechanisms, to improve their legal instruments and to increase their diplomatic capacity. The experience of such a regional organization after the Second World War, it means during and after the Cold War give us positive and negative models, efficient and inefficient work and in some extreme cases completely failure. History of regional organizations give learnt lessons for the time being and the times to come.

\section{Balkan, its experience}

Since almost one hundred years ago, the Balkans has experienced negative legacy toward regional cooperation. There were several reasons, some of them inherited from the history, the others coming up from the long and up and down transition toward democracy and Euro-Atlantic integration. The Balkan history during almost a century has been characterized by confrontations, conflicts, hatreds and rivalries which has produced more wars and less peace, more poverty less development, more isolations then integration, more bed famed international reputation then good image 
abroad. This legacy is not easy to overcome. It needs great reforms domestically and regionally. As a matter of fact, the situations on the ground has moved on after the Cold War.

Immediately after the "Berlin Wall" felt down, Central and Eastern European Countries started the process of transformation the political, institutional, economic and administrative aspects of states and societies. The aspiration to be the part of EuroAtlantic family promoted "Vishegrad Countries"1 and "Vilnius Countries"2 to work together regionally in order the process to be accelerated. In the contrary to this trend, the Balkans started by beginning of ' 90 the contradictory political dynamics causing dissolutions, fragmentations and wars among the confronted different states and ethnic groups ${ }^{3}$. It took very long time this regional conflicts and war to be solved, by all ways and means and deeply evolving international community.

Newly established democratic states faced a lot of domestic challenges. But the most serious challenge was the normalization of neighborhood policy and re-establishing of the new and democratic Regional cooperation process. So a lot of regional initiatives were established to bring stability on the post-war area such as SP 4; to develop economic cooperation BSEC 5; to open market further on both side from the east and the west, CEI 6; to manage the sea area of cooperation, All ${ }^{7}$; to cooperate in the field of security and NATO integration, Ach ${ }^{8}$, to improve the cooperation process entire Eastern Europe, SEECP 9; to exercise joint military activities, SEEBRIG ${ }^{10}$ etc. These regional initiatives brought a lot of positive impact, some more, some less, of course there some already failed. Anyway the process itself was relatively successful. So, now the Balkans is like the weather after the storm. Reconciliation, confidence building and dialog are going to replace the past and to open the new era of regional initiatives and cooperation. And after almost one hundred years, the Countries and the peoples in this Region ${ }^{11}$.

\section{Globalizaton trend}

Globalization seems to be the determinant trend towards a new world order once the cold war is over. I say "it seems", because there are many other opposing and contradicting trends and tendencies. Nevertheless, the majority of researchers are already recognizing globalization as the main trend of the $21^{\text {st }}$ century.

In a general view, it can be empirically stated that in a high level of political and economic development, globalization makes the tendency of de-nationalization of markets, policies and legal systems, so, in other words, marks the establishment of so called "global economy". At present, this is the definition, offered by the International Forum of Globalization, that leads the debates on this issue. This international debate involves international organizations, governmental institutions and the academic world and it is focused on the consequences of this political and economic reconstruction in local economies, people's wellbeing and environment in general.

In this phase, already distant from the first period of "Berlin Wall" fall, the debate on globalization is becoming more intense in an upward spiral way. On one side, there can be seen the supporters of globalization standards, headed by 'troika', International Monetary Fund ${ }^{12}$, World Bank ${ }^{13}$, World Trade Organization ${ }^{14}$. High representatives of these powerful

\footnotetext{
1 Vishegrad Countries, included three states, Hungary, Czechoslovakia and Poland

2 Vilnuis Countries, included Lithuania, Letonia and Estonia

${ }^{3}$ L.Bashkurti, "Political Dynamics of the Balkan Countries", Chikago Kent College of Law, Univerisy of Illynois, USA, 2004

4 Stability Pact, established, June, 1999

5 Black Sea Economic Cooperation, June, 25, 1992

${ }^{6}$ Center European Initiative, November, 11, 1989

${ }^{7}$ Adriatic lonian Inititive, October, 1999

${ }^{8}$ Adriatic Charter, May, 2, 2003

${ }^{9}$ South Eastern European Cooperation Processes, 1996

10 South Eastern European Brigade, September 26, 1998.

${ }^{11}$ Bashkurti, "Institucionet Ndwrkombwtare dhe Nismat Rajonale", UNS - ADSh, Macedonia, 2010

12 IMF - The International Monetary Fund was established in 1945 in order to help the world economy health. With its offices in Washington DC, it is guided and is responsible for 184 countries which make its membership almost global.

${ }_{13}$ The World Bank - is a vital source for financial and technical help for developing countries around the world. It is not a bank in the common meaning of the word. Its beginnings date back in 1944 and its offices are in Washington DC; it consists of two unique institutions for developmen accepted from 184 nations of the world: The International Bank for Reconstruction and Development (IBRD) and International Development Association (IDA).

14 WTO. The World Trade Organization is the only global and international organization that deals with the trading rules between the nations. It was established in Geneva, Switzerland, on 01/01/1995.
} 
international financial institutions are considered the principals of global economy, i. e. the fathers of open markets and free fair competition in international levels.

Leaders of "troika", take important decisions regarding the steps and methods of development that a nation or a society is to undertake and apply. They decide "who", "where" and "when", without mentioning "why" or "how". Globalization is becoming an "imposed" phenomenon of the market, starting with global institutions, not the national ones.

There is appearing a strong "underground", tendency and time to time comes on the surface and that one is opposing "troika" concerning globalization. According to this anti-globalization trend, of "troika" just a few minor disagreements are to be tolerated, the space for special cultures is small and it is becoming even narrower for local identities and at the same time workers and unionists rights should be reduced a lot.

Anti-globalization activists have raised the flag of "global environment protection". According to them, global environment, is protected with a great care from any kind of harm in northern industrialized countries (or western ones, depending on the observers location), but it is all left in the hands of international corporations in other parts of their economic activity. According to anti-globalization activists these corporations apply double standards, i. e. one in their countries, another one in developing countries. In developing countries, they do not care for the environment, as well as respective governments of these pitiable countries. Those governments are very little aware of the fact that they should reach as quickly as possible environmental standards alongside with the standards of development. Under such circumstances environment protection is considered just a luxurious matter that may even create problems.

But on the other side, globalization has many other opponents. Around the world there are unionists, environmentalists and human rights activists who fight against the idea of corporations for global markets that do not care about workers' rights, fair wages, environment protection and cultural diversity. Those opponents come from both sides of political spectrum, from the nationalist particularistic right wing and from international left wing generally. Someone, might even say that the so called anti - globalization is predominantly a concept of right wing in politics where nationalism, xenophobia and racism prevail.

The most appropriate definition of anti globalization trends would be "alter globalization", which means an alternative of globalization. Activists all over the world would like to make the world as a single society, one that would ensure wellbeing of all in contrary to the actual situation where billions of people are exploited in Asia, Africa and Latin America in a time when profits made by such global corporations are increasing in a spectacular way.

Confusion is the typical thing in situations when regionalism is considered as a sub global economic market. First of all, people in Regional levels do not live luxuriously as in the industrialized West, thus they will firstly be deluded by what is going to happen; they would exploit people from the third world and then would create their own ideas about morals and dilemmas surrounding them. On the other hand, privatization processes, restructuring of economies and increase of unemployment that result from all this are inevitably bringing the spirit of globalization initiated and strongly supported by 'troika'.

It is always good that for scientific reasons we could make the difference between the terms "globalism" and "globalization". According to contemporaneous order researchers "globalism", is defined in its substance as an international level phenomenon, beyond nation and region that marks a whole system of interdependent and interconnected networks that rise almost in an imposed way above multi-continental spaces. Systems of other networks are below this multi-continental level.

At the same time, the definition of "globalization" is more or less considered as the tendency of increasing or decreasing, dynamism or contraction of globalization level. "Globalization" focuses on forces, dynamism or speed of these developments. Thus, "globalism" is defined as the reality of interconnected inter-continental being, while "globalization" is defined as the dynamics of its development including the speed by which these connections are increasing or decreasing, developing or shrinking. Below, I will mainly focus on 'globalization'. And this is due to the fact that in the international debate, more and more they use the definition "globalism", as a trend or tendency which strongly supports the contemporaneous globalization process. 
Actually, in the levels of theoretic debate there exist many definitions for what globalization truly is. It can be basically said that these theoretical definitions are mainly characterized by subjectivist theory. That means that, they suffer from the influence of positions and experiences of the ones who have defined globalization, themselves. Mainly the subjectivist philosophical trend inclines the attitudes and thoughts of extreme character, for or anti-globalist ones. This creates and keeps open the debate.

In order to refer to this, let us emphasize a typical definition which at the same time is restricting compared to other trends and that is exactly the one defined by "troika", International Monetary Fund and World Bank. These two "troika" institutions have emphasized that globalism marks the economic interdependence which is constantly advancing in the countries around the world through the increase of capacity and variety of beyond - boundary transactions in goods and services, free international flow of capital as well as the speedy and wide delivery of technology.

Based on this "troika" definition, we are mostly dealing with so called economic globalism. Of course, a trend which supports so much pro- globalism extends its definition by "globalism" not considering it simply economic and commercial as "troika" defines it, but much broader. These ones have to agree with the definition that globalism is more than a civilization definition in increasingly open levels, with the inclusion of its economic, political, cultural and technological aspects which could be closely interlaced with each other. According to the last ones, economic globalism derives from civilizing globalism generally.

Based on what was previously mentioned, we can say that "Globalization" is a representative term for a complex of economic, social, technologic, cultural and political changes that are seen in the constant increase of interdependence, integration and interaction among people and companies in different countries of globe, "the world". The positive appraisers of globalization that consider it as a progressive development and whose basic principles they put together under these titles: secularism, liberal democracy, free market economy and legal constitutional state. Some others define this shortly with the terms: in the legal sphere, revolution of "human rights"; in political sphere, liberal democracy and in economic sphere, free market economy and production based on competition.

Of course, when the issue will have to be defined scientifically, the matter will be complicated even more. The difficulties start right with the definition of the concept. Neither the scientific debate nor the one of general public have a definition recognized by all as such. Below there are briefly introduced different efforts in defining the concept of globalization. According, to Elmar Altvater, "Globalization is a process of going beyond the historical border". By this Altvater, intends the same thing as diminishing or fading of national-state sovereignty and it is introduced as a separation of market economy from the set of moral rules and institutionalized obligations of societies..."

The other researcher of globalism, Anthony Giddens defines globalism as '.... Intensification of social relations all over the world, by which distant countries keep connected to each other in order that the events in a country are characterized by the same processes as in a country many kilometers away and vice versa..." The international analyst, Ulrich Menzel defines globalism as '...quantitative and qualitative intensification of cross border transactions during the simultaneous process of their local extension..." proceeding further, the researchers, Dirk Messner and Franz Nuscheler consider globalism as ...",The biggest economic and social change since industrial revolution...", or as Meghnad Desai calls globalism a "...increasing dependency and integration of different economies around the globe...", or "...a process of increasing connections between societies and problems...", the last one was a definition of Johannes Varwick.

Various researchers connect the definition of globalism to the process of globalization or more precisely do not separate the phenomenon from the process. Thus the researcher Christian von Weizacker defines globalism and globalization as follows ..." through globalization market competition is intensified...". Martin Schuman considers it as "... release of forces of global market and removal of economic power from states hands...".

Being somewhat more conclusive about what is globally happening, the researcher Martin Schuman emphasizes that globalism is already a phenomenon of the new world order and globalization as a dynamic process of its realization, "... already have become important words which are recently used in an inflationary way in political, journalistic and scientific debates, thus on one side are seen as a threat and on the other as a new opportunity...".

Generally in our economic, political, legal and civil sciences, the debate on globalism as a phenomenon and globalization as a process is far from being a scientific reality. Even though the country, economy and Albanian, regional and European culture are "slipping", if we could put it this way, in face of globalism and globalization, once more our sciences seem to be far behind. But without a scientific precedence of these strong tendencies of the new world order, policies can still wander 
blindly and enter into confusion and undertake action plans with fatal consequences for the country, economy, identity and civilization in general.

Yet the main reason of this article stands on the need to appeal to our researchers in order that they can start the process of scientifically analyzing the globalism tendency as a phenomenon of globalization development as a process in the context of consequences or chances that could be offered to the Albanian economy, identity and culture in open markets, integrated societies and in the approximate international thought.

\section{References}

[1] Adriatic Charter, May, 2, 2003

[2] Adriatic Ionian Inititive, October, 1999

[3] Black Sea Economic Cooperation, June, 25, 1992

[4] Center European Initiative, November, 11, 1989

[5] GAAT (The General Agreement on Tariffs and Trade) was first established from Bretton Woods Conference as part of a bigger plan for economic restoration after World War II. GAAT has involved a reduction of tariffs and other international obstacles and is generally considered as predecessor of the World Trade Organization.

[6] IMF - The International Monetary Fund was established in 1945 in order to help the world economy health. With its offices in Washington DC, it is guided and is responsible for 184 countries which make its membership almost global.

[7] L. Bashkurti, "Institucionet Ndwrkombwtare dhe Nismat Rajonale", UNS - ADSH, Macedonia, 2010

[8] L. Bashkurti, "Political Dynamics of the Balkan Countries", Chikago Kent College of Law, Univerisy of Illynois, USA, 2004

[9] South Eastern European Brigade, September 26, 1998.

[10] South Eastern European Cooperation Processes, 1996

[11] Stability Pact, established, June, 1999

[12] The World Bank - is a vital source for financial and technical help for developing countries around the world. It is not a bank in the common meaning of the word. Its beginnings date back in 1944 and its offices are in Washington DC; it consists of two unique institutions for developmen accepted from 184 nations of the world: The International Bank for Reconstruction and Development (IBRD) and International Development Association (IDA).

[13] Vilnuis Countries, included Lithuania, Letonia and Estonia

[14] Vishegrad Countries, included three states, Hungary, Czechoslovakia and Poland

[15] WTO. The World Trade Organization is the only global and international organization that deals with the trading rules between the nations. It was established in Geneva, Switzerland, on 01/01/1995.

\section{Authors of Globalism Refered to Artcile}

[1] Joseph Nye "Globalism Versus Globalization"

[2] Andre G. Frank dhe Barry K. Gills, "The Five Thousand Year World System: An Interdisciplinary Introduction"

[3] Ulrich Menzel "Post Westphalian Constellation, Nation's Misery and Globalization and Fragmentation Burden"

[4] Anthony Giddens, "The consequences of Modernity "(Polity Press, 1990

[5] Frederik Jameson, Masao Miyoshi, "Runaway World" (Routledge, 2000)

[6] David Held, Anthony Mc Grew, David Goldblatt, "Global Transformations " - 1999

[7] Princeton University Press, 2000, "The Globalization Syndrome"

[8] Martin Albrow, Stanfrod University Press, 1997, "The Global Age"

[9] David Held \&Anthony Mc Grew, 2000 "The Global Transformation Reader"

[10] Mark Rupert, "Ideologies of Globalization"(Routlege, 2000)

[11] Kenichi Ohmae, 1995, "The end of the Nation -State" 